
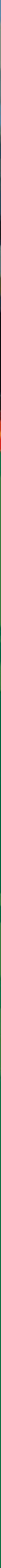


\section{0 \\ Bushfires at the urban-rural interface}

\section{Luke J. Balcombe}

Bushfire-prone areas of most concern to the Australian public, Governments and fire authorities are those where the economic costs and social/ environmental impacts are greatest. Such impacts of bushfire appear to have been experienced more intensely in the south-eastern states/ territory of Australia and to a lesser extent in Western Australia and Queensland. The most significant bushfire risks in Australia generally occur where populated areas meet with areas of bushfire risk - the areas referred to as the ruralurban interface.

\section{The rural-urban interface}

Rural-urban interface areas exist wherever homes and other developments are intermixed among trees and other combustible vegetation. The ruralurban interface or peri-urban developments in Australia are also known as the wildland-urban interface when referring to the equivalent in North America.

The conception of the physical layout of peri-urban locations needs some clarification according to Cottrell (2005):

Peri-urban zones can be totally new suburbs with small lot housing, shopping centres, service facilities, but essentially a suburb next to bushland. Peri-urban zones can also be large lot suburban developments. In many areas, they may be a mix of suburban and industrial zones as housing has spread into peripheral industrial estates. In other areas they may be conurbations gradually infilling unsettled areas on the periphery, and in yet other areas they may be encroaching on rural production (Cottrell, 2005, p. 110).

Communities in the rural-urban interface (areas on the fringes of cities) tend to feature relatively large populations living in close proximity to highlyflammable bushland areas. High fuel loads are often complicated by rugged topography with poor access and exit points. A high proportion of the inhabitants in these areas are commuters with little experience of living in 
the bush or fending for themselves in a major fire (Miller, Carter \& Stephens 1984). Nicholson (1995) suggests that "fringe communities are the most vulnerable part of the Australian and world wide environment" (p. 3).

In the context of bushfires there are four general types of urban-rural interface conditions that may occur:

1. Interface condition: Structures adjoin bushland fuels. There is a clear line of separation between structures and bushland fuels along roads or back fences.

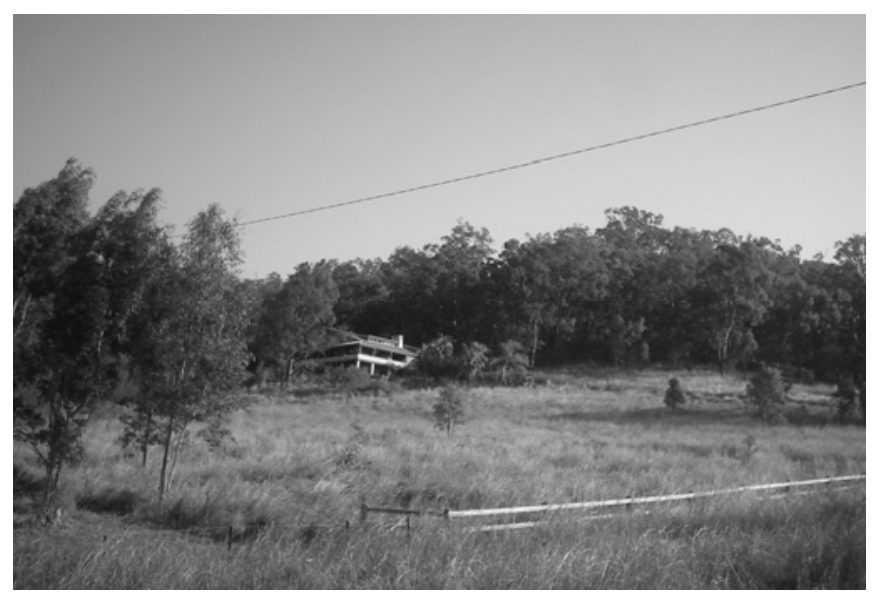

Figure 10.1 Interface condition - Tamborine Mountain, Queensland 
2. Intermix condition: Structures are scattered throughout the bushland area. There is no clear line of separation; bushland fuels are continuous outside of and within the developed area.

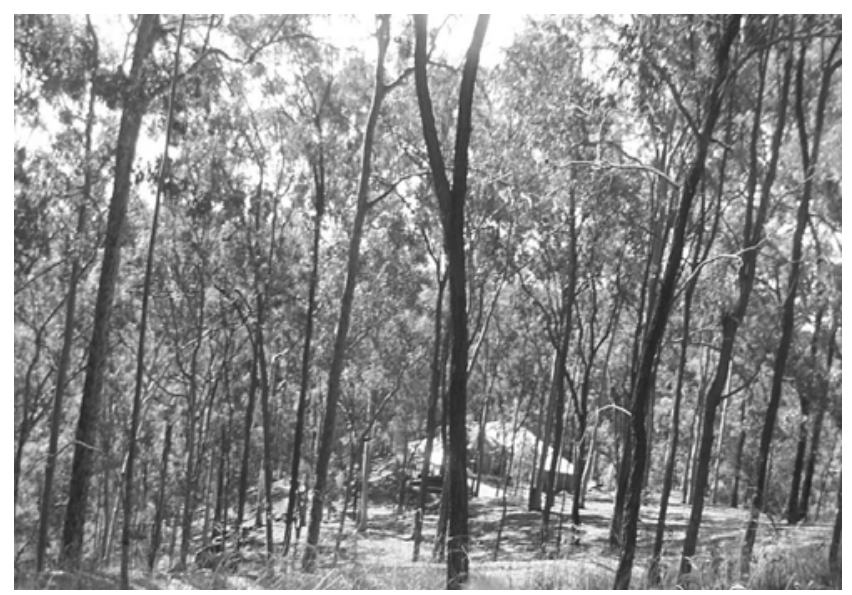

Figure 10.2 Intermix condition - Tamborine Mountain, Queensland

3. Occluded condition: Structures abut an island of bushland fuels, normally within a city, such as a park or other open space. There is a clear line of separation between structures and bushland fuels along roads or fences.

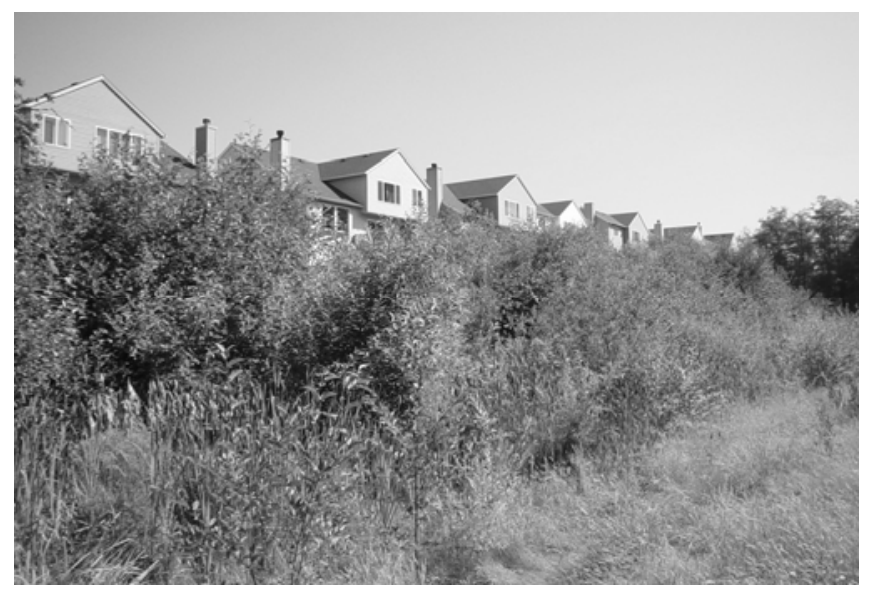

Figure 10.3 Occluded condition 
4. Rural condition: Scattered small clusters of structures (such as ranches, farms, resorts) are exposed to bushland fuels and there is much space between developments.

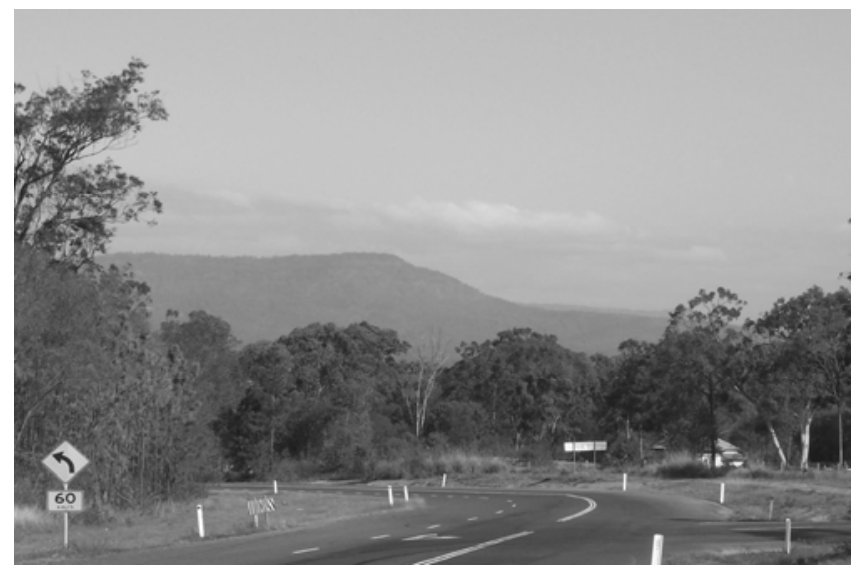

Figure 10.4 Rural condition - Tamborine Mountain, Queensland

In response to the devastating effects of the Canberra fires in J anuary 2003, there has been an increased interest within the Queensland Fire and Rescue Service (QFRS) in the identification and management of the urban-rural interface. The interface zone (i-Zone in Queensland) is where human population and flammable vegetation meet and is also known as the urbanrural interface zone. The classic example of this is where high-density housing is in close proximity to flammable vegetation, as was the case in Canberra (Type $1 \mathrm{i}$-Zone). Another type of dangerous interface zone is present in Australia, where rural residential properties are set amongst flammable vegetation and this has been identified as Type $2 \mathrm{i}$-Zone.

The GIS/ Risk Management division of QFRS undertook a project to identify these two types of i-Zone. They used two criteria for the model, firstly population density which was derived from a combination of land parcel size and proximity to the next property and secondly vegetation flammability (as identified in previous studies of bushfire risk). 


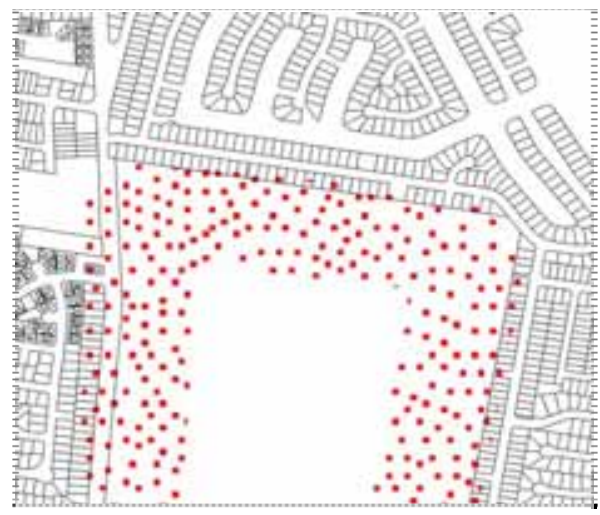

Figure 10.5 Type 1i-Zone

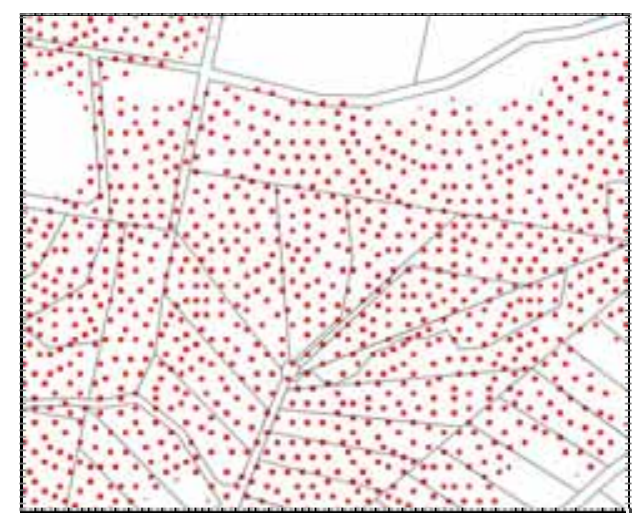

Figure 10.6 Type 2 i-Zone

The resulting categorisation identifies potential areas of concern for both urban and rural brigades. Specialised training for those personnel working within these areas of concern was identified by the QFRS as being required so as to reduce the potential risk of serious loss of structures and life. The two types of i-Zone are illustrated in Figures 10.5 and 10.6. Figures 10.7 and 10.8 (below) indicate where the two types of i-Zone can be found in the Mount Tamborine and the northern Gold Coast area.

The National Inquiry on Bushfire Mitigation and Management says that the i-Zone project is about holistic service delivery for communities in the ruralurban interface zone: "It is focused on Fire and Rescue Service personnel and how they can make a difference through a shift in culture, from separateness to inclusiveness" (Ellis, et al., 2005, p. 195). There is mention that the service providers can make gains by resolving i-Zone challenges in every aspect of service delivery, from the planning of new developments through to community education and awareness, service delivery planning, and response activities. 


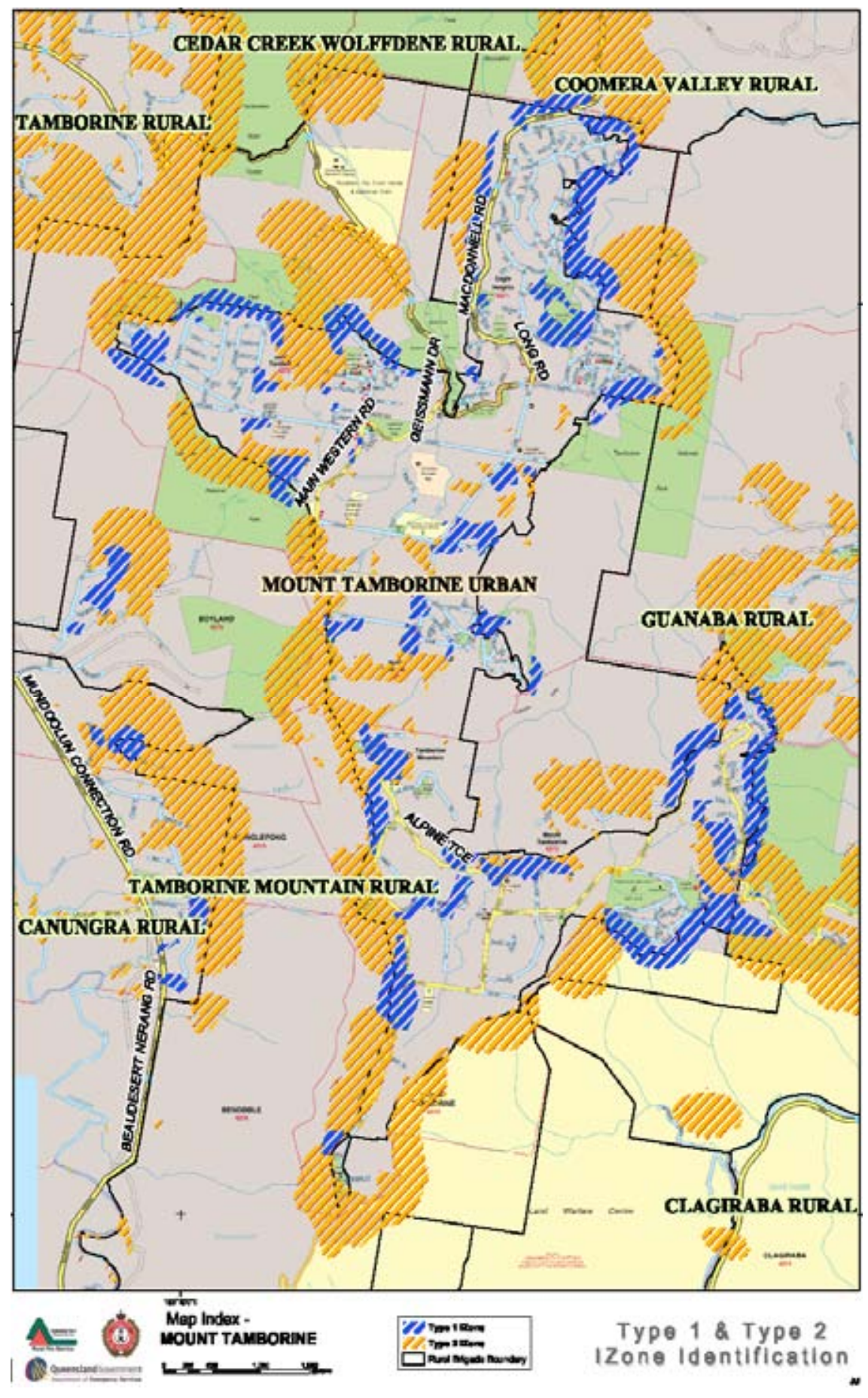

Figure 10.7

Mount Tamborine 


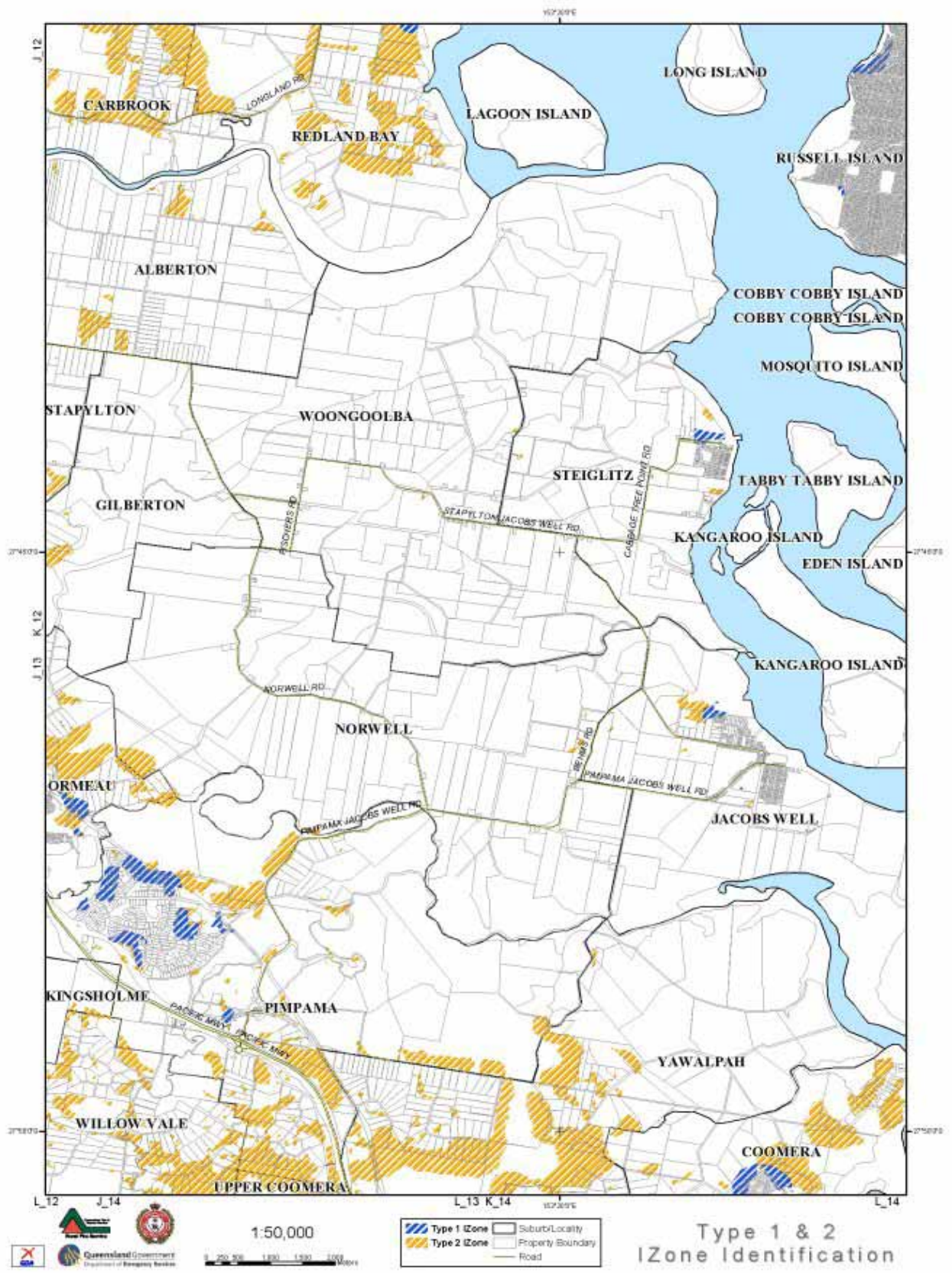

Figure 10.8 Northern Gold Coast 


\section{Current Situation}

Consequently, there is strong recognition that the interactions between the fire services and the communities they serve are crucial if there is to be successful avoidance of substantial losses to infrastructure and property, especially to interface zone housing. The legacy of some very poor planning decisions that were implemented three to four decades ago, exposing many interface zone housing areas to impact by high intensity fire is now apparent. As history has shown all too graphically, that threat can easily be realized whenever the necessary elements combine. A particular reason why interface zones are difficult to manage is that "appropriate planning protocols were not mandated until the mid 1980's, albeit in an ad hoc manner, with few of the necessary development controls keeping apace with new developments" (Koperberg, 2003, p. 2).

The impacts of fire upon the rural-urban interface are increasing for three primary reasons: fire suppression and less hazard reduction has led to increased fuel loads; fire risk has worsened due to drought conditions; and the population and density in areas of high fire risk is growing and ruralurban interface areas are growing rapidly, as more people seek to live in nonmetropolitan areas and near amenity-rich areas (Frentz, Farmer, Guldin \& Smith, 2004).

\section{Reconsidering the Future of the Interface}

The incidence of bushfire at the interface is dependent more on a set of environmental and human conditions than on a geographical location. Although the geographic location does dictate a set of general climatic conditions that encourage fires, the conditions in which interface zone fires occur (or have occurred) exist in nearly every community in the world. It is these conditional elements of weather, humidity, vegetation, building construction, road construction, lot size, housing density, topography, and other factors that simply make some communities more vulnerable to wildfire losses than others.

Smalley (2003) estimates that the most likely future is that "the grouth of communities into previously forested areas is one of the three major factors that will propagate the pressures of the interface on communities. The other two are unusually severe weather events (from prolonged drought to severe heating periods and floods that erode soils and vegetation) and inadequate infrastructure due to the rapidity of growth or aging" (p. 5). The issue of adequate infrastructure is the one that community-focused programs can most effectively change when implemented locally (Firewise Communities, 2003). It is more difficult to change the communities that already exist in 
hazardous conditions, however, there is a good opportunity to make wise fire-safety decisions at the outset of planning for new housing developments.

\section{Breaking the Cycle of Loss}

Planning for fire events and establishing creative incentives for encouraging homeowners to take appropriate responsibility are two things that community leaders should be doing immediately. Smalley (2003) warned that "insurance companies are not going to give significant premium adjustments for positive action, nor are they willing to increase premiums or cancel insurance for perpetuating hazardous conditions" (p. 7). Floods, earthquakes, cyclones and hailstorms are disasters that can be taken into account for adjusting insurance premiums, however, bushfires are an exception to this category. Reliable formulae to predict losses or project the mathematical expectations of wildfire occurrence are not available. Therefore, the data (loss and predictive) are not available to justify the financial decisions for adjusting rates and the bushfire risks that affect their bottom line.

What is needed are local solutions to encourage "doing the right thing". For example, if homeowners want to make improvements to their property (e.g. putting on a non-combustible roof) local government should provide real incentives. Perhaps waiving building permit fees for preventative improvements, waiving higher taxes on the preventative improvements, or providing community guidelines for preventative improvements would provide mitigating incentives. Homeowners, especially, must share the responsibility through active participation.

Smalley (2003) argues that "when the responsibilities are clearly defined and direction is provided, the paradigm of protector/victim is redefined" (p. 8). Firefighters and homeowners (along with other organizations) become partners. Community-wide and community-based fire protection can exist through mutually agreed-upon and mutually-respected responsibilities.

\section{Community Response during Bushfires}

The Australasian Fire Authorities Council (AFAC) has an agreed position in relation to community safety and evacuation during bushfires. Essentially this position advocates that where people have adequately prepared themselves and their houses and properties, they should remain with their homes during bushfires, rather than evacuate. Conclusive research conducted by agencies such as the CSIRO following major bushfires in Australia underpins this position. Most buildings lost in bushfires are the result of initially small fires started by sparks and embers. Buildings will 
generally survive the initial passage of a fire front providing adequate preparations have been made and providing people remain to extinguish small fires started in and around them. Exposure to dangerous levels of radiant heat created by bushfires is the greatest risk to people's safety. Consequently people who are prepared and take shelter in their homes are well protected from radiant heat. Last minute evacuations from bushfires are inherently dangerous and can create much greater risks than remaining in the fire area.

Most Australian fire authorities no longer support large-scale evacuation of people from areas threatened by bushfires. The approach advocated is to empower people and communities to take increased responsibility for their own safety. Gledhill (2003) advises that "this is a departure from the conventional paternalistic approach of emergency services in dealing with large-scale emergencies. It in many ways is a move back to the preemergency service era when communities were left to take care of their own safety" (p. 1). Such empowerment creates many advantages but also brings with it many challenges. Bushfires are a natural hazard which can be foreseen, prevented and combated to a greater degree than hazards such as severe storms, floods, earthquakes, tsunamis and volcano eruptions. Australian fire authorities have the challenge of reducing the negative impacts of bushfires on a community who increasingly wants to live close to the bush complete with all its natural attributes including fire hazards.

\section{Stay and Defend or Leave Early}

People who have not undertaken adequate preparation are advised not to stay and defend their property against bushfire. Where a house does not have sufficient defendable space and access to water supplies, the chances of saving it are greatly reduced and the danger for remaining occupants is increased. The advice therefore, for those people is to leave, but to do so early. Quite commonly in the Australian environment, because of the steep terrain and the rapid fire spread through spotting (fires started ahead of the fire by burning embers), there can be little warning time. Escape routes become blocked by smoke, fire, falling trees or power lines. In such cases when the dangers posed by escaping exceed those of remaining, clearly the best option is to stay.

The road systems in the interface and rural areas are typically not designed to handle high traffic flows and speeds, particularly when people are going in the opposite direction to responding fire appliances. The logistics of moving a lot of people quickly and safely make large scale evacuations very difficult. Television images of people with belongings packed, caught on blocked highways fleeing from danger are not uncommon. Even organized 
evacuations are not always orderly. Inexperienced and frightened people faced with evacuation from a terrifying fire may behave irrationally. Being told to go by authority figures - police or fire officers, is the final signal that all is far from okay. Seeing and hearing people in authority anxiously urging people to leave sends a very strong message that disaster is imminent.

The responsibility or duty of care of those who order evacuations is such that they are answerable to ensure that the evacuees are safe during the transit process as well as being safe in the chosen refuge. While fleeing from danger is a normal human instinct and not being there is the safest option, as discussed above there are many reasons why this is not a practical or safe option. Fire events are very dynamic and place specific. The orientation of the interface and the road network with respect to a fire front or series of fire fronts, as well as smoke effects make it very difficult to realistically simulate or predict bushfires. The inclusion of community factors such as demographics, community expectations and identification with the bush, and previous bushfire experience increase the difficulty of pre-incident planning.

AFAC implicitly accepts that there will be occasions, hopefully very rare, where a person will be killed by staying with their home. In such cases where a person's life is immediately at risk by them being in a particular location (in the opinion of the on-scene fire or police officer) they may be advised to evacuate. Should the advice be not heeded, then in most States, legislation enables evacuation to be ordered (with force if necessary).

Evacuation as a safety strategy has in the past been supported and employed in the belief that people are prone to panic and irrational behaviour when faced with an unfamiliar and threatening emergency situation. Evacuation from a bushfire can itself result in some people being exposed to greater safety risks at times, as well as often resulting in much greater property losses. In the absence of residents, property has to be defended by often limited fire-fighting resources. If people are well informed, prepared and empowered, they are capable of taking appropriate actions to protect themselves and their property without the need for evacuation or close supervision and direction by emergency services. Such active community involvement will free up fire fighting and emergency resources, allowing their more effective deployment.

\section{Lessons from a major bushfire at the urban-rural interface January 2003}

The Canberra fires of J anuary 2003 provided a special opportunity to draw conclusions from a fire that impacted on the critical area of interface zones 
and was readily observed by fire-fighters, scientists and members of the community. Four people died and many more suffered injuries. The fire had a significant impact on urban dwellings and burnt large areas of natural and commercial forest. Over 500 dwelling were destroyed. The Canberra fires reflected the characteristics of many other bushfires because they occurred in natural Australian bushland as a result of lightning strikes and they were of little media interest initially as they were in the hills. The issue of greatest concern was the destruction which occurred at the interface during one afternoon. Ellis (2003) described the following features of the fires that were unusual and make them of special interest:

“- $\quad$ they were well observed throughout the event

- a series of fires joined to create a super conflagration with unique characteristics

- the impact into the suburban fringe extended far beyond the initial street of houses" (Ellis, 2003, p. 1).

In the end, protection from bushfire is reliant on individual householders. During the Canberra fires in January 2003, individual residents or their neighbours saved the vast majority of homes. While fire-fighters may be in a position to assist, in all probability during a major bushfire, it will be individual planning, actions and preparations that will most likely determine whether they and their home survive. It is inevitable in Australia that bushfires will occur again. The outcome from those bushfires is dependent on the partnership between fire authorities managing the overall event and attacking and defending against the bushfire and individuals protecting their own lives and property.
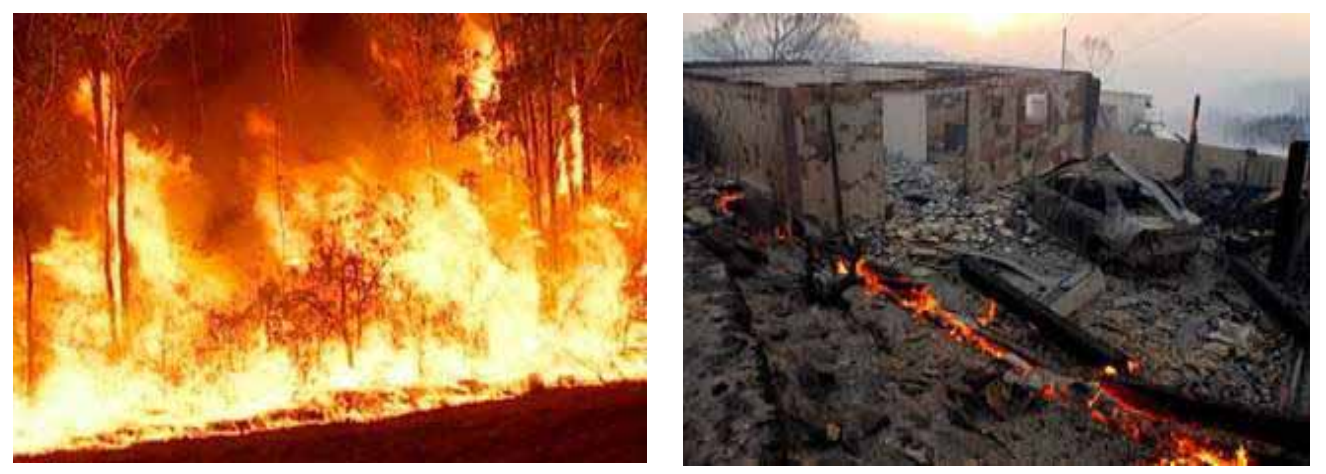

Figures 10.9 and 10.10 Canberra bushfires, J anuary 2003

Finally, the Canberra fires indicated to the Government that money spent on fire prevention and response is an investment in the future safety and 
sustainability of the community and although it comes at a cost, this cost is far less than the cost of community recovery after such a devastating event. Ellis (2003) noted that "fire prevention and preparation for response is insurance, and needs to be viewed as a valuable risk management approach" (p. 5). The Canberra fire event of 2003 developed into a firestorm that few had seen before and Canberra has not experienced on its urban fringe for many years. Unfortunately many of the lessons identified in Canberra are lessons re-learnt across the industry. However, this tragedy provides a powerful opportunity for the industry to reinforce these lessons and ensure communities are better prepared in the future.

\section{Social Considerations of the Interface}

The social issues sparked by bushfire are as diverse as the needs and uses of fire. Careful consideration of social norms and culture, economic needs and history of communities must be given to issues of suppression, fuel reduction, prevention, education, and other activities. What may be an acceptable practice in one location may have negative or even disastrous consequences elsewhere. What may seem a logical and practical step in one place may out of the question in another, solely due to social values. Indeed, social considerations may be as vital to the success of a prevention activity as a well-prepared shift plan or having the proper equipment available is to a suppression effort. Hamilton (2003) said "that community support is a direct result of a sense of community initiative and ownership, and not from a top-down, mandated approach" (p. 1).

The best of intentions and the best in technology are not guarantees that fuel loads will be reduced in the critical areas where homes and bushfire meet at the interface. As Hamilton (2003) notes, "Wildland-urban interface neighborhoods are social systems. Failure to work with the social system will probably doom efforts to promote fire hazard mitigation" (p. 1). The challenge to fire management leaders in Australia is to address these issues, exchange ideas and techniques, involve and listen to communities, and work toward solutions in individual neighbourhoods. It is only through the initiative and commitment of neighbourhoods and communities that prevention and education programs will make more permanent the changes that are needed to reduce fire danger to people and their possessions. Understanding what stakeholders think about bushfire, and linking these cognitive patterns (e.g. value orientations, social norms) to management actions, is an important first step in developing a scientific means to inform bushfire educational and communications programs. 


\section{Future Challenges}

Educating people in at-risk-from-bushfire communities about bushfire preparation is a significant challenge. Empowerment must extend beyond people knowing what to expect and how to react when threatened by bushfire. The stay and defend strategy is only effective if it is preceded by adequate preparation. Preparation isn't necessarily just creating a defendable space, but also mental preparation - knowing what to expect. Gledhill (2003) warned that "fire services need to be realistic in what they communicate to people in fire situations. The success of the strategy relies heavily on the people in affected communities making appropriate decisions. For that they need to have access to timely and accurate information about the fire situation" (p. 5). The emergency managers in those communities also need to conform to the policy. Gledhill (2003) also claims that "police and others need to accept that people will want to stay with their homes and need to be supported in place. They too need timely and accurate information". Whilst that seems reasonable, gathering timely and accurate information and communicating it to the people needing it, presents a considerable challenge. Gledhill (2003) identified that "whilst most firefighters appreciate the importance of accurate and up-to-date information, few have seen a need to provide it to the people at risk" (p. 6). The empowerment and consequent effectiveness of residents is dependent on them also having good information.

\section{Public Agencies Assisting Community-Based Solutions}

Increasingly, fire agencies recognize that they cannot protect all citizens from all bushfires. The limitations of both rural and municipal fire agencies become most evident during major fires at the interface (Boura, 1999; Cohen, 1999; Rohrmann, 1999; Tasmania Fire Service, 1994; Smith et al, 1991). Citizens too, are beginning to recognize that neither land management agencies nor local fire authorities can maintain fire suppression capabilities sufficient to conserve private property under extreme fire conditions. With this recognition, comes a growing understanding that the private property owner bears a margin of responsibility for protecting his or her own safety and property (Boura, 1999; Cohen, 1999; Ingalsbee, 2003, Waldron, 2001).

Progressive fire authorities are adapting to this changing operational environment by empowering people to take responsibility for their own safety and developing their own fire mitigation strategies. In fact, experience suggests that people will rigorously implement fire prevention and mitigation strategies only if they have helped develop them (Beckingsale, 1994; Boura, 1999; J urie, 2000). 
Progressive public fire agencies will adapt to this changing operational environment by recognizing the importance of empowering people to take responsibility for their own safety and developing their own fire mitigation strategies. DeGrosky (2003) stated that many of our best solutions are "community-based solutions which allow groups of people to rally around a commonly perceived problem that threatens their community; agree on the nature of the problem; and tackle it" (p. 1). Highly successful community efforts produce durable results, and derive from processes that are participatory, inclusive and highly collaborative. Successful communitybased solutions also require "community capacity," or an ability to act. A combination of commitment, resources and skills that a community can deploy represents that community's capacity to address a problem. Public agencies across Australia are exploring ways in which they can initiate and facilitate community efforts, build community capacity, develop commitment and produce lasting results.

Increasingly, "community-based solutions" provide effective, and perhaps the best, solutions to public policy issues. DeGrosky (2003) stated that "successful community-based solutions typically share three essential characteristics. First, they are collaborative. Second, they are inclusive. Finally, they get people involved, resulting in commitment that allows durable or lasting results" (p. 2). The desired outcomes of self-reliant communities adequately preparing themselves and their homes for bushfire are much more likely to occur in the future if there are steps towards a realistic resolve in tackling the "what-ifs".

\section{Collaboration}

In regard to community initiatives, collaboration occurs when people with different viewpoints work together to foster mutual understanding, build agreement and resolve disputes regarding community issues (Helling, 1998; Margerum, 2002; McKinney, 1998). According to Helling (1998), "collaboration creates a temporary forum within which consensus about the problem can be sought, mutually agreeable solutions can be invented, and collective actions to implement the solutions can be taken" (p. 336) The value of a collaborative process lies in the ability to produce inclusive, sustainable results that people implement with commitment. However, community organizers may also encounter members of community groups and task forces who view the act of collaborating as a sufficient accomplishment in itself. Given the growing desire for processes that produce results, public fire authorities hoping to foster community-based solutions to fire problems with lasting results would be wise to measure their success by the results produced, rather than simply by the tools they use. 


\section{Inclusion}

Successful community initiatives involve those people affected by the issue, those needed to implement any agreement, and anyone who may undermine the process if not included (McKinney, 1998). This description provides an effective definition of a class of people commonly known as "stakeholders." Helling (1998) provides an alternative definition, characterizing stakeholders as "all individuals, groups or organizations that are directly influenced by actions others take to solve the problem" (p. 336). In practical terms stakeholders are parties with an interest in an issue and may include individuals, groups of people, organizations or institutions.

Successful community-based solutions typically evolve from efforts that include all relevant stakeholders, regardless of perspective. Efforts primarily driven by agencies, without sufficient involvement by stakeholders, run the risk of rejection by the community as "just another government program". The success of community initiatives facilitated by government agencies (whether the local volunteer fire department or the Federal government) largely depends on conscious decisions that the facilitators make about inclusion and cooperation. No formula exists for determining the appropriate degree of inclusiveness and collaboration for a given project or circumstance. However, most often, as involvement and participation go up, commitment and potential for success follow.

There exists a tension and a system of competing forces. DeGrosky (2003) explained this is because "collaborative approaches nearly never accomplish work expediently. The value of collaboration lies in the potential for higher quality and more lasting outcomes that a group effort brings". While public agencies naturally, and rightly, seek a compact and efficient public process, with each decision the organizers make to exclude people or groups, they lessen the likelihood that those people or groups will feel like they are an adequate part of the plan or decision. DeGrosky (2003) warned that "stakeholders, unsatisfied with their role or influence in a process, rarely support the resulting decision or plan. Similarly, with each decision that the organizers make to reduce collaboration, in other words to reduce the influence the group has over the process, the problem definition, the solutions and implementation, the greater the possibility that people will grow unsure, apathetic, resistant or hostile to the decision, plan or solution" (pp. 3-4).

\section{Involvement, Participation and Commitment}

To succeed, community-based initiatives require commitment both by the involved communities and by the involved public agencies. A community 
achieves commitment when it obtains sustained support throughout implementation of the solution, agreement or decision. Commitment to community-based solutions requires the active participation of community members. Doyle (2001) asserts that implementation will be incomplete and will be likely to fail without participation.

With perspectives on the responsibility of the private property owner shifting, public fire authorities have shown increasing interest in empowering people to take responsibility.

Ideally, a group of people rallies around a commonly perceived problem, agrees on its nature, and finds and implements the solutions to the problem with a high degree of commitment. Unfortunately, as DeGrosky (2003) advises, "this kind of effort remains relatively uncommon, particularly because they require public agencies and their staffs to relinquish a degree of control that they have traditionally maintained, and often require agencies and their personnel to significantly alter their relationship and approach to the community" (p. 5). Typical efforts organized by public agencies allow for public involvement, and they increasingly include most, if not all, stakeholders. However, DeGrosky (2003) explained that "too often, agency led efforts fail to meet the expectations of either the agency or the community. One reason is that, even when inclusive, communities perceive agency-based efforts as token, insincere or somewhat coercive" (p. 5). Too often, public agencies simply go through the motions of involving the public, bringing groups of people together merely for the purpose of fulfilling legal requirements or to create the impression of "public involvement." In today's operational environment, they do so at their peril; as half- hearted or lessthan-sincere efforts tend to breed distrust and can produce the unintended consequence of inspiring the active resistance of citizens.

Herein lies a relatively new and evolving role for the public fire agency. This new role builds upon and enhances, rather than diminishing or replacing, the traditional function of the fire service. Progressive fire authorities increasingly recognize their role as community capacity builders and their responsibility to create awareness, motivate community members to take responsibility, and to facilitate community-based solutions (Frank \& Smith, 2000; Lipnack \& Stamps, 2000). Most communities will need the assistance of a fire agency as they develop their community-driven fire mitigation responses. For example, in an evaluation of Community Fireguard programs in Victoria, Rohrmann (1999) found that a considerable degree of guidance and direction is necessary in order to get resident groups activated and eventually taking responsibility for improving fire preparedness. 


\section{Fostering Community-based Solutions}

The Australian Community Fireguard programs provide an example of an effective collaborative approach through which public fire authorities enable community-based solutions and help communities to build capacity. Community Fireguard initiatives provide a unique case study because the program has existed for ten years. Both anecdotal evidence and scholarly research offer evidence that this community-based approach benefits residents in fire-prone areas and improves fire risk mitigation by both individuals and the community. Preliminary findings by Rohrmann (1999) found considerable potential for the Community Fireguard concept, and offer encouragement that inclusive, participatory and highly collaborative fire mitigation efforts can achieve durable results that originate from the community (Beckingsale, 1994; Boura, 1999; Rohrmann, 1999; Tasmania Fire Service 1994).

Originally conceived by the Country Fire Authority (CFA) in Victoria, Community Fireguard programs have spread to other Australian states including New South Wales, South Australia and Tasmania. This community-based initiative allows groups of people to come together, agree on the nature of a fire problem threatening their community, craft solutions that make sense for the community, and develop "community capacity," or an ability to act. According to Boura (1999), Community Fireguard programs "involve small groups of people living in high fire risk areas, taking responsibility for their own fire safety and working together to devise survival strategies which suit their own situation" (p. 6). Most Community Fireguard groups are self-initiated by members of the community.

The proportion of a community who effectively prepare for a bushfire varies greatly. Recent large-scale studies of community response to bushfire include the survey of 1200 residents affected by the NSW 2001 fires undertaken by Rhodes (2003) on behalf of AFAC, and a major quantitative study of preparedness in Victoria completed in 2002 by CFA. Rhodes (2003) found that "in some of the surveyed communities approximately half the population might be considered moderately to well prepared. However, in many communities the level of preparedness was lower, with a large proportion of the population poorly informed and prepared" (p. 9). There are many factors that are likely to determine the extent to which people become prepared. One of these factors is the extent to which the community is exposed to information and programs to increase preparedness. Evaluation of CFA community education programs (Rohrmann, 1999) indicate that such programs do lead to increased preparedness, but also that change is not uniform for all participants and that it is incremental and occurs over the long term. 
When it comes to fostering community-based solutions, the appropriate role for public fire agencies depends on the circumstances and on the agency's needs and motivations. The agency may choose to remain in the traditional role of community educator, stakeholder or other vested participant; convene the collaborative process; or facilitate the group effort. Depending on the circumstances, all the roles described here may prove appropriate for public fire agencies, and all can fit into a community-based, collaborative process. DeGrosky (2003) advises that "to effectively influence communitybased initiatives, public fire agencies must consciously decide and make clear the agency's role and its motivations for participating" (p. 6). Given the growing desire for processes that produce results, public fire authorities hoping to foster community-based solutions producing lasting results are advised by DeGrosky (2003) to "assure that the collaborating parties establish objectives for the outcome of the process and articulate criteria for evaluating results" (p. 9).

\section{Successful community programs}

Successful community programs share the following five common traits:

1. Identify the particular interface bushfire problems of the community

Interface zone bushfire problems are different throughout the country and have the potential to develop in all states and affect communities of any size. Therefore, cause and effect of bushfires are a significant factor to consider in planning for local, regional and national contexts.

\section{Define roles for the affected agencies and individuals}

Changing attitudes and behaviour is a complex task even when the goal seems simple in attempting to reduce the threat from bushfire faced by people, homes and natural resources. The value of involving all of the affected agencies has long been understood. The roles of the members of the working team must be defined to improve efficiency and to prevent wasted or duplicated effort. The best organizational effort will be able to harness the strengths of each team member. Roles are best defined when the process is done formally, in writing.

\section{Secure inter-agency cooperation}

The value of inter-agency cooperation is clear in that a team/ group can accomplish more than an individual when the goal affects a large number of people. The tough part is getting separate agencies with different priorities and perspectives to work together. To help this cooperative process, the U.S. 
National Interagency Fire Center published six steps to help improve fire protection effectiveness.

The six steps from the National Interagency Fire Center (NIFC, 2001) include the following:

- $\quad$ Obtain the commitment of the separate agencies to work together;

- $\quad$ Examine your problems together;

- $\quad$ Set joint goals and objectives;

- $\quad$ Develop programs and policies;

- $\quad$ Approve and implement the plan;

- $\quad$ Evaluate and revise the program as needed.

4. Develop public support

If lack of public awareness of interface zone bushfire safety contributed to the dangerous conditions seen in many areas, better public education will be a key element in improving those conditions. The first task, and the hardest, is to get the public's attention. To reach varied audiences with such a wide demographic range requires an extensive and intensive media campaign involving a maximum sharing of information about every aspect of the problem.

5. Implement, coordinate and evaluate programs.

Ultimately, it takes action to change public attitudes and behaviour regarding bushfire safety. The successful programs show that there is no single answer or approach that will produce perfect fire safety in every community under all conditions. Good planning is essential, but eventually those plans must be translated into programs that are implemented and coordinated to keep them on target. After the programs get under way, an objective evaluation helps measure the success and serves to refocus efforts as needed to improve success. 


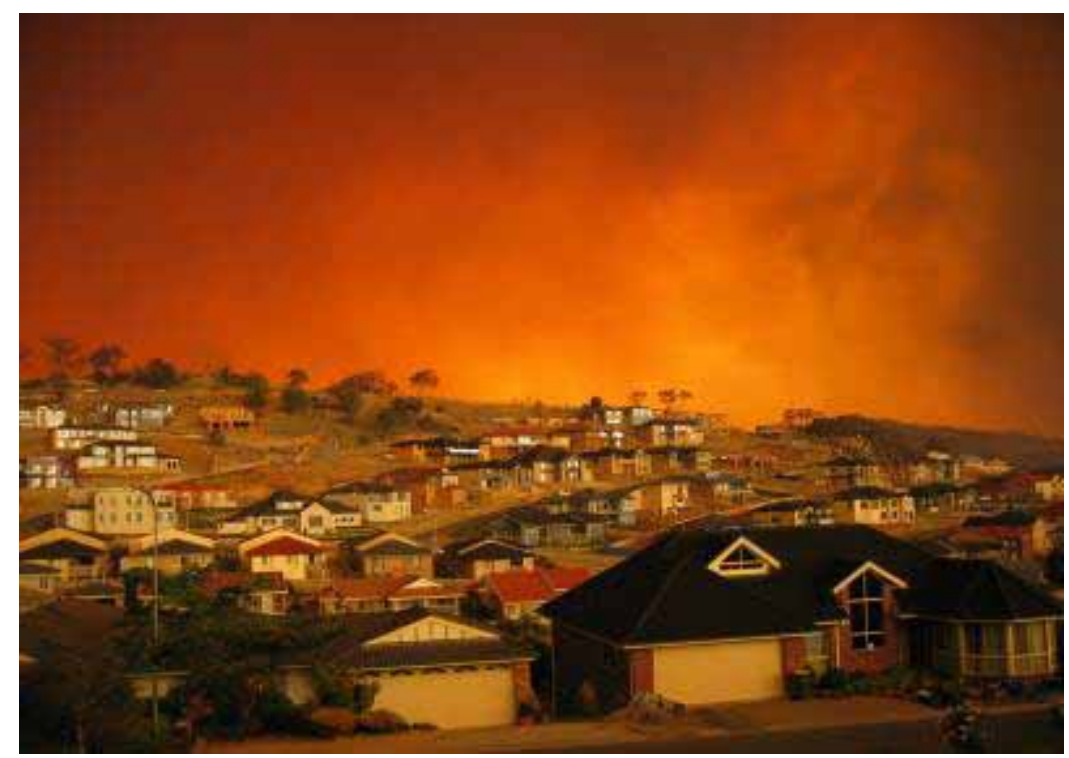

Figure 10.11Canberra bushfires, J anuary 2003

Interface bushfire management requires collaborative partnerships for planning, implementation and evaluation of global concepts on the local landscape level. Over time, it is hoped that fire services help communities to become more self-reliant.

\section{Conclusions}

As more people move out of cities to the interface, tragic and disastrous bushfires will inevitably occur. Whilst people, directly and indirectly, are by far the greatest cause of bushfires in Australia, controlling people and their use or abuse of fire is not a realistic or practical solution. Empowering the communities at risk from bushfire to play an active part in their own safety and in the protection of their assets in partnership with the fire services is a viable long-term strategy to enable safe co-existence with fire as a natural element of the environment. The combined efforts of fire protection services, legislators, planners, developers, land owners and homeowners will be required to prevent tragic loss of lives and homes at the interface. For fire services to provide these communities with effective protection from bushfire requires a holistic approach based on the needs and aspirations of all community members. In many instances the local community that is potentially at risk needs to be educated on those risks and the consequences of action, as well as inaction, if they choose to ignore the risks.

Australia has realised that long-term planning and commitment from all levels of government can sustain investment in research and development 
for safer communities, economic development and fuels management and forest health. Collaboration is required among the many stakeholders to assess and prioritise which interface zones and landscapes to concentrate on and to reconcile conflicting management objectives. 